\title{
Evaluating the benefits of home-based peritoneal dialysis
}

\author{
This article was published in the following Dove Press journal: \\ International Journal of Nephrology and Renovascular Disease \\ 4 December 2014 \\ Number of times this article has been viewed
}

\section{Karlien François Joanne M Bargman}

Division of Nephrology, University Health Network Toronto General Hospital, University of Toronto, Toronto, ON, Canada
Correspondence: Karlien François Division of Nephrology, University Health NetworkToronto General Hospital, 200 Elizabeth Street, Toronto, ON, M5G 2C4, Canada Email karlien.francois@uzbrussel.be
Abstract: Peritoneal dialysis (PD) is an effective renal replacement strategy for patients suffering from end-stage renal disease. PD offers patient survival comparable to or better than in-center hemodialysis while preserving residual kidney function, empowering patient autonomy, and reducing financial burden to payors. The majority of patients suffering from kidney failure are eligible for PD. In patients with cardiorenal syndrome and uncontrolled fluid status, PD is of particular benefit, decreasing hospitalization rates and duration. This review discusses the benefits of chronic PD, performed by the patient or a caregiver at home. Recognition of the benefits of PD is a cornerstone in stimulating the use of this treatment strategy.

Keywords: peritoneal dialysis, survival, quality of life, cost, home dialysis

\section{Introduction}

The unique characteristics of the peritoneal membrane allow its use as an endogenous dialyzing membrane. The vast capillary network within the peritoneal connective tissue covered by a mesothelial cell layer serves as a semipermeable membrane, allowing solute and water transfer between the intravascular space and dialysate fluid dwelling in the peritoneal cavity. Since peritoneal dialysis (PD) began to be used in the late 1970s, practice patterns have evolved continuously. Improvements in peritoneal access and catheter design, dialysate solutions, connectology, exit site management and peritonitis prevention strategies and the growing use of automated PD have led to improved patient- and technique outcomes over the last decades.

Outcome comparisons for patients treated with different forms of renal replacement therapy require a strict methodological approach adjusted for selection bias, potential confounders, effect modifiers, and lag-time effect after renal replacement therapy modality transfers. A randomized controlled trial (RCT) would be the ideal way to evaluate dialysis modality outcomes; however, RCTs are difficult to perform. A recent attempt at an $\mathrm{RCT}^{1}$ comparing initial dialysis modality was prematurely stopped given the low inclusion rate. Recruitment difficulties related to patients' modality preference after education as well as to the significant differing impact on lifestyle between PD and center hemodialysis (HD) interfered with the feasibility of this RCT. Data from observational studies comparing outcomes between different modalities of renal replacement therapy need critical appraisal, taking into account potential limitations such as selection bias and residual unmeasured or uncollected confounders.

In 2008 , only $11 \%$ of the dialysis population worldwide was treated with $\mathrm{PD}^{2}$ The prevalence varies significantly between regions, with the proportion of dialysis patients 
on PD being as high as $79 \%$ in Hong Kong. ${ }^{2}$ Education of health care professionals and patients regarding this treatment strategy and its benefits is key for improving PD use.

For this narrative review, we searched PubMed for articles published in English up to August 2014, without a specific start date. Full-text articles were used in most cases, and references were searched for additional relevant articles. We discuss eligibility for home PD, highlighting clinical, psychosocial, and financial benefits of home PD and focusing on data from the recent literature on contemporary practices (Table 1). We provide data on outcome studies comparing PD and HD when available.

\section{Peritoneal dialysis: who?}

Although various guidelines and papers differ with respect to potential contraindications for PD (Table 2), ${ }^{3-7}$ clinical evidence of ineligibility for PD in these particular circumstances is often lacking. It is our opinion that very few medical contraindications exist for PD. Active inflammatory bowel disease and recently inserted ostomies are medical reasons to withhold PD, given that they are associated with increased risk for PD-related peritonitis and leak, respectively. In contrast, PD has been successfully performed in patients with failed kidney transplant, ${ }^{8,9}$ after liver, ${ }^{10,11}$ lung, ${ }^{10}$ and cardiac $^{10,12}$ transplant, in patients with a history of repair of abdominal aortic aneurysm ${ }^{13}$ or major abdominal surgeries, ${ }^{14-16}$ in patients with established ostomy, ${ }^{17}$ in patients with abdominal wall or inguinal hernias, ${ }^{18}$ in obese patients, ${ }^{19}$ in black $^{20}$ patients, and in patients with polycystic kidney disease $^{21,22}$ or diverticulosis. ${ }^{23}$ In the latter, holding PD during an acute episode of diverticulitis is warranted to prevent secondary enteric peritonitis. Data from large registries show technique and patient survival are not affected by family income or educational level. ${ }^{24,25}$ Both Dutch and Canadian observational studies confirmed that the majority of patients are eligible for PD. ${ }^{3,26}$

The sole condition to start PD is having a peritoneal cavity and a working PD access. Approaches for peritoneal

Table I Benefits of peritoneal dialysis

Most ESRD patients are eligible for PD
Similar survival between PD and HD
Effective solute and water removal
Slower decline in residual kidney function compared to HD
Declining risk in PD-related peritonitis over the last decades
Technically simple
Greater autonomy and independence for patients compared to facility-HD
Lower actual cost compared to HD in most countries

Abbreviations: ESRD, end-stage renal disease; HD, hemodialysis; PD, peritoneal dialysis. catheter insertion vary. Peritoneal cavity access can be created by open or laparoscopic surgical techniques or by percutaneous puncture of the abdomen by nephrologists or interventional radiologists. Important advantages for having a nephrologist perform PD catheter insertion are better continuity of care and reduced waiting time. Moreover, the success rate is similar to that of surgicallyinserted PD catheters. ${ }^{27-29}$ Supine intermittent PD can be immediately started after PD catheter insertion, avoiding temporary HD.

\section{Peritoneal dialysis at home}

Except for a clean corner in the home, a closet-sized area to store dialysis fluid, and a facility for hand washing with clean running water, no additional requirements exist for performing PD at home. If (elderly) patients are not able to operate the different steps needed for PD exchanges, support by a trained caregiver or home care nurse might enable the patient to benefit from home PD. Canadian data from the province of Ontario showed an increased eligibility for PD if home care assistance is available, ${ }^{30}$ and European studies have confirmed the success of assisted PD for survival and peritonitis outcomes. ${ }^{31,32}$

\section{Peritoneal dialysis: why? Clinical benefits of home peritoneal dialysis}

\section{Survival}

Data used to compare survival between dialysis modalities are derived from large observational studies and registry analyses. Common findings of these studies are a similar overall patient survival between $\mathrm{PD}$ and HD with a potential survival benefit for PD in younger patients, nondiabetic patients, and patients receiving PD during their first 1-3 years of dialysis. ${ }^{33-38}$

A large US Renal Data System analysis published by Mehrotra et $\mathrm{al}^{33}$ in 2011 compared survival for patients treated with in-center HD and home PD. Overall, the relative risk of death for PD and HD over 5 years of follow-up was not significantly different (adjusted hazard ratio $[\mathrm{HR}]=1.03$, $95 \%$ confidence interval $[\mathrm{CI}]=0.99-1.06$ ) within their most contemporary cohort of patients starting dialysis between 2002 and 2004. Subgroup analysis of this contemporary cohort of patients by age (younger and older than 65 years of age), with or without comorbidities (defined as cerebrovascular, cardiovascular or peripheral vascular disease, diabetes mellitus [DM], chronic pulmonary disease, or malignant neoplasm) showed a survival advantage for PD throughout 
Table 2 Described contraindications and barriers to PD

\begin{tabular}{|c|c|c|c|c|c|}
\hline & $\begin{array}{l}\text { Jager } \\
\text { et } \mathrm{al}^{3}\end{array}$ & $\begin{array}{l}\text { Blake } \\
\text { et } \mathrm{al}^{4}\end{array}$ & $\begin{array}{l}\text { Oliver } \\
\text { et } \mathrm{al}^{5}\end{array}$ & $\begin{array}{l}\text { Covic } \\
\text { et } \mathrm{al}^{6}\end{array}$ & $\begin{array}{l}\text { National Kidney } \\
\text { Foundation }^{7}\end{array}$ \\
\hline Previous major abdominal surgery or abdominal scarring & ++ & ++ & ++ & & \\
\hline Planned abdominal surgery & & & ++ & & \\
\hline Cystic kidneys & ++ & & ++ & - & \\
\hline Poor lung function & ++ & & & & \\
\hline Chronic inflammatory bowel disease & ++ & & ++ & & + \\
\hline Acute diverticulitis & & ++ & ++ & & \\
\hline Diverticulosis & & & & - & \\
\hline Frequent episodes of diverticulitis & & & & & + \\
\hline Ischemic gut & & & ++ & & + \\
\hline Bowel cancer & & & ++ & & \\
\hline Obesity & ++ & ++ & ++ & - & + \\
\hline (Large) abdominal wall hernias & & ++ & ++ & - & ++ \\
\hline Abdominal wall ostomies and conduits & & ++ & ++ & & ++ \\
\hline (Large) abdominal aortic aneurysm & & ++ & ++ & & \\
\hline Documented loss of peritoneal function & & & & & ++ \\
\hline Extensive abdominal adhesions limiting dialysate flow & & & & & ++ \\
\hline Fresh intra-abdominal foreign bodies ( $<4$ months) & & & & & + \\
\hline Severe malnutrition & & & & & + \\
\hline Abdominal wall or skin infections & & & & & + \\
\hline Body size limitations & & & & & + \\
\hline Congestive heart failure & & & & - & \\
\hline Portal hypertension & & & & - & \\
\hline Liver transplantation & & & & - & \\
\hline Ascites & & & ++ & & \\
\hline Insufficient physical strength & & + & & - & \\
\hline Impaired vision & & + & & - & \\
\hline Impaired hearing & & + & & - & \\
\hline Immobility & & + & & - & \\
\hline Poor health and frailty & & + & & - & \\
\hline Poor hygiene & & + & & & \\
\hline History of nonadherence & & + & & - & \\
\hline Psychiatric illness & & + & & - & \\
\hline Dementia or poor memory & & + & & - & \\
\hline Language barriers & & + & & - & \\
\hline Patient inability to perform PD exchanges him/herself & ++ & & & - & \\
\hline Place of residence does not permit PD & & ++ & ++ & - & \\
\hline Employment does not permit PD & & & ++ & & \\
\hline
\end{tabular}

Notes: ++ considered a contraindication for PD. + considered a barrier to PD. - not considered a contraindication for PD.

Abbreviation: PD, peritoneal dialysis.

the 5 years of follow-up for the younger, nondiabetic patients without comorbidities. Mortality was lower during the first 12 months for nondiabetic patients presenting with one or more comorbidities treated with PD and during the first 24 months for nondiabetic patients older than 65 years without comorbidities. Young diabetic patients without comorbidities presented a similar survival for both dialysis modalities, whereas hemodialysis mortality was significantly lower in older diabetic patients as well as in younger diabetic patients with at least one comorbidity. Kumar et al ${ }^{34}$ used US data from a registry of all Kaiser Permanente Southern California patients with end-stage renal disease (ESRD) to compare survival between PD and HD. More than 1,000 incident PD patients between 2001 and 2013 were 1:1 propensity matched to incident HD patients who started dialysis after predialysis care and with a permanent vascular access. After 9 years of follow-up, a similar survival for PD and HD was found, with an early survival advantage for PD, for almost 3 years and 2 years in an as-treated and intention-to-treat analysis, respectively. ${ }^{34}$ According to this cohort selection, the higher early mortality for HD patients cannot be attributed to urgent-start HD or the use of central venous catheters.

It is noteworthy that mean administered hemodialysis dose in the United States is lower compared to other parts of 
the world, potentially overestimating the favorable effects of PD outcomes in the Mehrotra et al and Kumar et al studies compared to regions with higher administered hemodialysis doses. However, survival data from countries with higher facility HD doses ( $3 \times 4$ hours weekly and more) and higher proportion of PD use, hence less potential selection bias, confirm the overall survival similarity between PD and HD. ${ }^{35,36}$ Canadian data did not show an early survival benefit for PD in patients starting dialysis after predialysis care ${ }^{37}$ or compared to HD patients starting dialysis with a permanent vascular access. ${ }^{38}$ Quinn et $\mathrm{al}^{37}$ analyzed survival differences between PD and HD using Ontario administrative health data on patients starting dialysis between 1998 and 2006, while avoiding bias introduced by acute or unplanned dialysis start. The authors showed an overall similar survival in patients starting dialysis electively as an outpatient after at least 4 months of predialysis care, with an adjusted HR of 0.96 (95\% CI $=0.88-1.06$ ) throughout a 2-year follow-up period. Including urgent dialysis starters in the analysis, the authors found an early survival benefit for PD starters beyond 2 years for nondiabetic patients. For diabetic patients, a survival benefit of up to 2 years was found if all outpatient dialysis starts were included; however, PD was associated with a higher risk for death in diabetic patients who survived the first 90 days of dialysis. Importantly, when PD patients were compared to elective-start HD patients as a whole, there was neither an early survival advantage nor a late survival disadvantage for PD. ${ }^{37}$ Canadian Organ Replacement Registry data for patients starting dialysis between 2001 and 2008 were used by Perl et $\mathrm{al}^{38}$ to assess the effect of vascular access type at the start of HD on early survival differences between HD and PD. Stratifying HD patients according to their first HD access, adjusted HR for 1-year mortality was $1.8(95 \% \mathrm{CI}=1.6-1.9)$ for patients starting with a central venous catheter but only $0.9(95 \% \mathrm{CI}=0.8-1.1)$ for patients starting with an arteriovenous fistula or arteriovenous graft. Similar to previously discussed data, DM attenuated the mortality risk of HD compared to PD in both the central venous catheter and arteriovenous fistula/arteriovenous graft subgroups. ${ }^{38}$

A recent publication by Marshall et $\mathrm{al}^{36}$ evaluating mortality risks in New Zealand ESRD patients commencing dialysis between 1997 and 2011 showed an overall equivalent survival for PD and facility $\mathrm{HD}$, with a $20 \%$ lower mortality risk associated with PD during the first 3 years of PD. This study indeed pointed to a longer duration of early survival benefit for PD compared to facility HD than was described previously. Regarding the effect modification by
DM, this study was found to reverse the survival benefit for PD compared to facility HD only after 3 years and only for patients suffering from DM type 2. DM type 2 patients on PD for more than 3 years showed a $28 \%$ higher mortality risk $(95 \% \mathrm{CI}=1.10-1.50)$ compared to facility HD. In the first 3 years on PD, however, the presence of DM was not associated with an increased mortality risk compared to incenter HD (DM type 1: $\mathrm{HR}=0.38[95 \% \mathrm{CI}=0.20-0.73]$ and DM type 2: $\mathrm{HR}=0.92[95 \% \mathrm{CI}=0.80-1.05])$. Marshall et $\mathrm{al}^{36}$ did not identify a modification of survival effect by age or comorbidity (cerebrovascular, cardiovascular or peripheral vascular disease or chronic lung disease).

In conclusion, in the absence of randomized controlled trials and to the extent that registry data can be analyzed, survival is comparable between the two modalities. Therefore, the choice of dialysis therapy for a patient should not be made on the basis of length of survival.

\section{Solute clearance and ultrafiltration}

The three-pore model describes solute and water flux across the peritoneal capillaries using a concept of three types of pores: ultrasmall pores or aquaporins that allow solute-free water transport, and small and large endothelial pores that allow flux of smaller and larger molecular-weight solutes, respectively. The ionic content of PD fluid (PDF) consists of sodium, chloride, calcium, magnesium, and a lactate or bicarbonate-lactate-based buffer. Diffusive transport of solutes is driven by a concentration gradient between the blood compartment and the intraperitoneal dialysate. Diffusion occurs through the small and large pores and, given that it is concentration dependent, is most effective for molecules that are not contained in the PDF, eg, creatinine, urea, potassium, phosphate, and other uremic toxins. Water transport is achieved by an osmotic gradient across the peritoneal membrane.

In commercially available PDF, osmotic forces are generated in two different ways. Hypertonic PDFs are made by adding dextrose $\left(\right.$ Dianeal $^{\circledR}$ and Physioneal ${ }^{\circledR}$ by Baxter, IL, USA; or BicaVera ${ }^{\circledR}$ and Balance ${ }^{\circledR}$ by Fresenius, Bad Homburg, Germany) or amino acids (Nutrineal ${ }^{\circledR}$ by Baxter) to the dialysis solution. Water removal through the aquaporins and small pores results from the osmotic gradient between the hypertonic PDF and the blood in the peritoneal capillaries. The higher the osmotic gradient is (ie, higher dextrose concentration), the greater the ultrafiltration will be. During a PD dwell with a dextrose-based solution, glucose will be absorbed into the blood compartment. Using low dextrose concentrations and long dwell times, the 
osmotic gradient dissipates and water can be reabsorbed. An oncotic pressure gradient in favor of water removal over the small and large pores can be generated by an isoosmotic PDF supplemented with the maltodextrin-derived icodextrin (Extraneal ${ }^{\circledR}$ by Baxter). Fluid uptake by the lymphatic system can negatively affect net ultrafiltration. The characteristic of ultrafiltration during PD is a continuous gentle fluid removal. Hence, PD is considered to offer more hemodynamic stability than conventional hemodialysis. Convective removal of solutes occurs together with the water removal driven by any type of osmotic gradient. The functional surface area of the peritoneum mainly determines the peritoneal clearance of low molecular weight solutes and ultrafiltration, while macromolecular clearance also depends upon intrinsic pore size.

Peritoneal small solute clearance can be calculated by determining 24-hour peritoneal effluent volume and concentrations of small solutes together with blood levels. However, peritoneal small solute clearance is not a good predictor of survival when residual kidney function is present. ${ }^{39}$ Indeed, reanalyzed Canada-USA Peritoneal Dialysis Study Group (CANUSA) data showed greater renal glomerular filtration rate (GFR) and increased urine output to be associated with relative risk reduction of death: $\mathrm{HR}=0.88$ (95\% CI $=0.83-0.94)$ for every $5 \mathrm{~L}$ increase in weekly GFR, and $\mathrm{HR}=0.64(95 \% \mathrm{CI}=0.51-0.80)$ for every 250 $\mathrm{mL}$ increase in daily urine volume. In contrast, increased peritoneal creatinine clearance was not associated with the relative risk of death $(\mathrm{HR}=1.0[95 \% \mathrm{CI}=0.90-1.11]$ for every $5 \mathrm{~L}$ increase in weekly peritoneal creatinine clearance). ${ }^{39}$ The European APD Outcome Study (EAPOS) trial evaluating outcomes in anuric European patients treated with cycler PD identified age, comorbidity, and amount of ultrafiltration (UF), but not small solute clearance, as predictors of outcome. ${ }^{40}$

\section{Residual kidney function}

An important contributor to survival and overall health of dialysis patients is residual kidney function (RKF). ${ }^{39,41-44}$ Therefore, strategies to preserve RKF need to be applied during follow-up of dialysis patients: use of reninangiotensin-aldosterone system blockade, ${ }^{45}$ avoidance of nephrotoxins (nonsteroidal anti-inflammatory drugs, aminoglycosides, radiocontrast agents), and avoidance of hypovolemia. Several studies suggest PD to be associated with a slower decline in RKF, compared to HD. ${ }^{46-48}$ Potential mechanisms for the superiority of PD in preserving RKF are its greater hemodynamic stability, reduced ischemic kidney insult, and lack of inflammatory mediators generated from the extracorporeal hemodialysis circuit.

\section{Peritoneal dialysis-related peritonitis}

Peritonitis remains a clinically important complication of PD. Morbidity resulting from PD-related peritonitis is significant, with some episodes being complicated by hospitalization and temporary or permanent transfer to HD. Inflammatory processes during severe, recurrent, relapsing, repeated or refractory peritonitis can lead to peritoneal membrane failure and the need to discontinue PD. Current International Society of Peritoneal Dialysis guidelines recommend a PD program's peritonitis rate to be less than 1 per 18 patient-months or 0.67 per year at risk. ${ }^{49}$ Over the last decades, a declining rate of peritonitis has been described. ${ }^{50-52}$ Major factors contributing to improved peritonitis rates are improvements in connectology, antibiotic prophylaxis before catheter insertion and at the time of invasive procedures, and antibiotics routinely at the exit site. Additional contributing factors include organizational aspects, such as continuous quality improvement initiatives and home visits. ${ }^{53} \mathrm{PD}$-related peritonitis is a manageable complication, is often treatable on an outpatient basis, and has high cure rates. ${ }^{52}$

\section{Special consideration for patients with congestive heart failure}

Controlling fluid status in patients suffering from congestive heart failure complicated by progressive renal insufficiency, ie, cardiorenal syndrome type 2 (CRS2), is challenging, especially in the setting of diuretic resistance. In that case, renal replacement strategies are used for ultrafiltration. Theoretical advantages in favor of the use of PD rather than any form of intermittent or continuous hemodialysis are its gentle continuous ultrafiltration (avoiding neurohormonal pathway activation), being a permanent outlet from the abdominal cavity (thus keeping intra-abdominal pressure and venous congestion at their lowest), removing sodium efficiently, improving potassium levels (hence allowing [increased] use of renin-angiotensinaldosterone system blockers) and offering these benefits at home. Retrospective studies evaluating clinical effects of PD in patients with CRS2 showed significant reduction in number and duration of hospitalizations after initiation of PD, ${ }^{54-56}$ improved functional New York Heart Association classification, ${ }^{54,56,57}$ and improvement in left ventricular ejection fraction ${ }^{54,55}$ at an acceptable cost of PD-related morbidity. ${ }^{55-57}$ Continuous ambulatory PD (CAPD) was the main PD modality in these studies, all limited by the absence of a comparator group treated with an alternative renal replacement modality. 
A prospective study evaluating the effects of CAPD in CRS2, although limited by small sample size $(n=25)$ and the absence of an HD comparator, showed improved quality of life, New York Heart Association functional classification, and 6-minute walk test results 6 weeks and 24 weeks after the start of PD compared to baseline. ${ }^{58}$ In the 6 months following PD start, this study also showed a decreased number of hospitalization days for acute heart failure compared to the 6 months prior to CAPD.$^{58}$ Whether hospital admissions and length of stay are reduced due to PD itself or because fluid status is better controlled, independently of the way this is achieved, is unclear. Indeed, number of and duration of hospitalizations for cardiovascular causes, but not for all causes, was reduced for both PD (nightly intermittent PD or CAPD) and HD in a prospective nonrandomized study evaluating beneficial effects of both dialysis modalities. ${ }^{59}$ After initiation of PD or HD, quality of life and functional status improved. ${ }^{59}$ In this study, cumulative survival with HD versus PD was not significantly different, although a beneficial trend for PD was noted. More (randomized) studies are needed to compare outcome differences between PD and HD as a strategy to control fluid balance in CRS2. Nonetheless, data regarding reduction in hospital admissions and length of stay after initiation of PD in subjects suffering from CRS2 are consistent. Therefore, PD should be considered as an excellent strategy to achieve fluid control in CRS2.

Unexpectedly, a discrepancy was noted between outcomes of PD in CRS2 versus CRS type 4, a type of cardiorenal syndrome in which primary chronic kidney disease contributes to decreased cardiac function. US ${ }^{60}$ and French ${ }^{61}$ retrospective registry-based studies both showed higher mortality risks for patients with ESRD and congestive heart failure when treated with PD compared to HD. However, generalizability of these data is limited. The US study applies to a 1990s population, an era prior to widespread icodextrin use, with short follow-up (2 years). Several factors warrant careful interpretation of the French study: congestive heart failure was only characterized as per nephrologists' judgment, no discrepancy was made between New York Heart Association functional classification III and IV, and survival was only calculated from day 90, potentially underestimating HDassociated early mortality.

\section{Psychosocial benefits of home peritoneal dialysis}

In contrast to in-center HD, PD offers greater flexibility to patients as to time management: 1) patients treated with PD are (or should be) trained to adapt the PD prescription to their daily activities if needed, and 2) a PD clinic visit is scheduled every 4-12 weeks compared to thrice weekly for patients treated with in-center HD. Also, the technical simplicity of PD allows patients to perform dialysis while traveling, without need for facility support. In every respect, PD offers increased autonomy and independence to patients suffering from end-stage renal disease compared to facility $\mathrm{HD}$, and this is reflected in higher employment rates for patients treated with home PD compared to facility HD. ${ }^{62-64}$ Evidence that the greater autonomy associated with PD leads to an improved quality of life is weak ${ }^{65}$ although many studies suggest at least equivalent or better quality of life for patients treated with PD compared to in-center HD. ${ }^{66-70}$ As to patient satisfaction with their dialysis care, a prospective cohort study involving 37 dialysis centers in the United States showed patients treated with PD rated their care higher than did patients treated with facility HD. ${ }^{71}$ Assisted PD, whereby PD is administered with the help of a trained caregiver, could support the autonomy and independence of disabled or elderly persons suffering from kidney failure. ${ }^{72,73}$ Arranging transportation to the hemodialysis unit several times a week is often burdensome for these patient groups, and they might not be home hemodialysis candidates, given comorbidities or living circumstances.

\section{Financial benefits of peritoneal dialysis}

The nature of PD itself, the decreased staff-to-patient ratio, and lower overhead explains a lower actual cost for PD compared to HD from a health care system perspective, ie, the payer. ${ }^{63,74-79}$ Both direct costs, ${ }^{77-79}$ expenditures borne by the health care system, community, and patient in addressing the illness, and indirect health care costs, ${ }^{63}$ productivity losses to society caused by the dialysis modality, are significantly reduced in patients treated with PD compared to HD. US data show the annual cost for dialysis care is $\$ 24,293$ higher for patients treated with facility HD compared to PD. ${ }^{79}$ In a propensity-matched cohort of incident US dialysis patients, the overall health care related costs over the first year of treatment was $\$ 43,510$ higher for HD compared to PD. ${ }^{77}$

PD bears an economic advantage even for patients presenting with PD technique failure. A Canadian cohort study showed PD technique failure to be associated with significant lower costs by $\$ 11,466$ at 1 year and similar costs at 3 years compared with HD only ${ }^{80}$ For patients transitioning from HD to PD compared to HD only, this study also showed a significant financial benefit of $\$ 26,050$ and $\$ 61,652$ at 1 year and 3 years, respectively. These savings were mainly driven by dialysis cost savings. ${ }^{80}$ 
An important direct cost in dialysis patients is related to the use of erythropoietin stimulating agents. A large DaVita registry analysis comparing the use of erythropoietin stimulators in prevalent $\mathrm{PD}$ and $\mathrm{HD}$ patients found three to four times higher doses of these agents in HD compared to PD, despite similar distribution of hemoglobin and even when adjusted for hemoglobin, case mix, and malnutrition-inflammation syndrome.$^{81}$ It is self-evident that the actual cost for assisted PD is higher compared to self-care PD yet European and Canadian data show assisted PD is still cost-effective when compared to in-center HD. ${ }^{30,82,83}$

Actual dialysis cost and reimbursement differ, and overall, reimbursement rates for home dialysis are lower than those for hospital HD. ${ }^{84}$ Nonetheless, reimbursement adjustments incentivizing PD did not increase the use of $\mathrm{PD}$ in Germany ${ }^{85}$ and Ontario. ${ }^{86}$ The dialysis provider will indeed balance reimbursement incentives for home dialysis against the high initial investment cost for every hemodialysis unit whereby the per capita cost increases when more dialysis stations remain unused. Therefore, a health care system will only have sustained economic benefits from increased PD use if equal reimbursement strategies for different dialysis modalities are supported by physician recognition of clinical and psychosocial benefits of PD and by appropriate training of health care professionals to empower patients with knowledge and freedom to perform dialysis at home.

\section{Conclusion}

The majority of patients presenting with kidney failure can be treated with PD, an effective dialysis modality with similar overall survival at lower cost compared to HD. An additional advantage of home PD is its intrinsic empowerment of the patient. Every patient preparing for renal replacement therapy should receive education concerning all options for dialysis.

\section{Disclosure}

Joanne M Bargman is a consultant for Amgen and Baxter Global, and is in the Speaker's Bureau for DaVita Healthcare Partners and Baxter Global. Karlien François reports no conflicts of interest in this work.

\section{References}

1. Korevaar JC, Feith GW, Dekker FW, et al; NECOSAD Study Group. Effect of starting with hemodialysis compared with peritoneal dialysis in patients new on dialysis treatment: a randomized controlled trial. Kidney Int. 2003;64(6):2222-2228.

2. Jain AK, Blake P, Cordy P, Garg AX. Global trends in rates of peritoneal dialysis. J Am Soc Nephrol. 2012;23(3):533-544.
3. Jager KJ, Korevaar JC, Dekker FW, Krediet RT, Boeschoten EW; Netherlands Cooperative Study on the Adequacy of Dialysis (NECOSAD) Study Group. The effect of contraindications and patient preference on dialysis modality selection in ESRD patients in The Netherlands. Am J Kidney Dis. 2004;43(5):891-899.

4. Blake PG, Quinn RR, Oliver MJ. Peritoneal dialysis and the process of modality selection. Perit Dial Int. 2013;33(3):233-241.

5. Oliver MJ, Garg AX, Blake PG, et al. Impact of contraindications, barriers to self-care and support on incident peritoneal dialysis utilization. Nephrol Dial Transplant. 2010;25(8):2737-2744.

6. Covic A, Bammens B, Lobbedez T, et al. Educating end-stage renal disease patients on dialysis modality selection: clinical advice from the European Renal Best Practice (ERBP) Advisory Board. Nephrol Dial Transplant. 2010;25(6):1757-1759.

7. National Kidney Foundation. II. NKF-K/DOQI Clinical Practice Guidelines for Peritoneal Dialysis Adequacy: update 2000. Am J Kidney Dis. 2001;37(1 Suppl 1):S65-S136.

8. Perl J, Dong J, Rose C, Jassal SV, Gill JS. Is dialysis modality a factor in the survival of patients initiating dialysis after kidney transplant failure? Perit Dial Int. 2013;33(6):618-628.

9. Yang KS, Kim JI, Moon IS, et al. The clinical outcome of end-stage renal disease patients who return to peritoneal dialysis after renal allograft failure. Transplant Proc. 2013;45(8):2949-2952.

10. Cornelis T, Rioux JP, Bargman JM, Chan CT. Home dialysis is a successful strategy in nonrenal solid organ transplant recipients with end-stage renal disease. Nephrol Dial Transplant. 2010;25(10):3425-3429.

11. Shukla AM, Lobbedez T, Chu M, Izatt S, Bargman JM, Oreopoulos DG. Peritoneal dialysis in end-stage renal disease after liver transplantation. Adv Perit Dial. 2004;20:93-97.

12. Chen YC, Chou NK, Hsu RB, et al. End-stage renal disease after orthotopic heart transplantation: a single-institute experience. Transplant Proc. 2010;42(3):948-951.

13. Schmidt RJ, Cruz C, Dumler F. Effective continuous ambulatory peritoneal dialysis following abdominal aortic aneurysm repair. Perit Dial Int. 1993;13(1):40-44.

14. Attard JA, Attard A. Laparoscopic right hemicolectomy in an automated peritoneal dialysis patient without removal of the PD catheter: a case report. Case Rep Surg. 2014;2014:492567.

15. Schoenmaeckers EJ, Woittiez AJ, Raymakers JF, Rakic S. Continuous ambulatory peritoneal dialysis after intra-abdominally placed synthetic mesh for ventral hernia repair. J Laparoendosc Adv Surg Tech A. 2011;21(8):741-743.

16. Torigoe T, Akiyama Y, Uehara T, Nakayama Y,Yamaguchi K. Laparoscopic colectomy for transverse colon cancer in an automated peritoneal dialysis patient: a case report. Int J Surg Case Rep. 2013;4(7):640-642.

17. Lew SQ, Gruia A, Hakki F. Adult peritoneal dialysis patient with Tenckhoff and percutaneous endoscopic gastrostomy catheters. Perit Dial Int. 2011;31(3):360-361.

18. Balda S, Power A, Papalois V, Brown E. Impact of hernias on peritoneal dialysis technique survival and residual renal function. Perit Dial Int. 2013;33(6):629-634.

19. Prasad N, Sinha A, Gupta A, et al. Effect of body mass index on outcomes of peritoneal dialysis patients in India. Perit Dial Int. 2014;34(4):399-408.

20. Fernandes NM, Hoekstra T, van den Beukel TO, et al. Association of ethnicity and survival in peritoneal dialysis: a cohort study of incident patients in Brazil. Am J Kidney Dis. 2013;62(1):89-96.

21. Li L, Szeto CC, Kwan BC, Chow KM, Leung CB, Kam-Tao Li P. Peritoneal dialysis as the first-line renal replacement therapy in patients with autosomal dominant polycystic kidney disease. Am J Kidney Dis. 2011;57(6):903-907.

22. Lobbedez T, Touam M, Evans D, Ryckelynck JP, Knebelman B, Verger C. Peritoneal dialysis in polycystic kidney disease patients. Report from the French peritoneal dialysis registry (RDPLF). Nephrol Dial Transplant. 2011;26(7):2332-2339.

23. Toda S, Ito Y, Mizuno M, et al. Asymptomatic diverticulosis identified by computed tomography is not a risk factor for enteric peritonitis. Nephrol Dial Transplant. 2012;27(6):2511-2516. 
24. de Andrade Bastos K, Qureshi AR, Lopes AA, et al; Brazilian Peritoneal Dialysis Multicenter Study (BRAZPD) Group. Family income and survival in Brazilian Peritoneal Dialysis Multicenter Study Patients (BRAZPD): time to revisit a myth? Clin J Am Soc Nephrol. 2011;6(7): 1676-1683.

25. Yang ZK, Han QF, Zhu TY, et al. The associations between the family education and mortality of patients on peritoneal dialysis. PLoS One. 2014;9(5):e95894.

26. Prakash S, Perzynski AT, Austin PC, et al. Neighborhood socioeconomic status and barriers to peritoneal dialysis: a mixed methods study. Clin J Am Soc Nephrol. 2013;8(10):1741-1749.

27. Chula DC, Campos RP, de Alcântara MT, Riella MC, do Nascimento MM. Percutaneous and surgical insertion of peritoneal catheter in patients starting in chronic dialysis therapy: a comparative study. Semin Dial. 2014;27(3):E32-E37.

28. de Moraes TP, Campos RP, de Alcântara MT, et al; Investigators of BRAZPD. Similar outcomes of catheters implanted by nephrologists and surgeons: analysis of the Brazilian peritoneal dialysis multicentric study. Semin Dial. 2012;25(5):565-568.

29. Medani S, Hussein W, Shantier M, Flynn R, Wall C, Mellotte G. Comparison of percutaneous and open surgical techniques for first-time peritoneal dialysis catheter placement in the unbreached peritoneum. Perit Dial Int. Epub July 31, 2014.

30. Oliver MJ, Quinn RR, Richardson EP, Kiss AJ, Lamping DL, Manns BJ. Home care assistance and the utilization of peritoneal dialysis. Kidney Int. 2007;71(7):673-678.

31. Povlsen JV, Ivarsen P. Assisted automated peritoneal dialysis (AAPD) for the functionally dependent and elderly patient. Perit Dial Int. 2005; 25 Suppl 3:S60-S63.

32. Verger C, Duman M, Durand PY, Veniez G, Fabre E, Ryckelynck JP. Influence of autonomy and type of home assistance on the prevention of peritonitis in assisted automated peritoneal dialysis patients. An analysis of data from the French Language Peritoneal Dialysis Registry. Nephrol Dial Transplant. 2007;22(4):1218-1223.

33. Mehrotra R, Chiu YW, Kalantar-Zadeh K, Bargman J, Vonesh E. Similar outcomes with hemodialysis and peritoneal dialysis in patients with end-stage renal disease. Arch Intern Med. 2011;171(2):110-118.

34. Kumar VA, Sidell MA, Jones JP, Vonesh EF. Survival of propensity matched incident peritoneal and hemodialysis patients in a United States health care system. Kidney Int. Epub July 2, 2014.

35. Yeates K, Zhu N, Vonesh E, Trpeski L, Blake P, Fenton S. Hemodialysis and peritoneal dialysis are associated with similar outcomes for endstage renal disease treatment in Canada. Nephrol Dial Transplant. 2012;27(9):3568-3575.

36. Marshall MR, Walker RC, Polkinghorne KR, Lynn KL. Survival on home dialysis in New Zealand. PLoS One. 2014;9(5):e96847.

37. Quinn RR, Hux JE, Oliver MJ, Austin PC, Tonelli M, Laupacis A. Selection bias explains apparent differential mortality between dialysis modalities. J Am Soc Nephrol. 2011;22(8):1534-1542.

38. Perl J, Wald R, McFarlane P, et al. Hemodialysis vascular access modifies the association between dialysis modality and survival. $J \mathrm{Am} \mathrm{Soc}$ Nephrol. 2011;22(6):1113-1121.

39. Bargman JM, Thorpe KE, Churchill DN; CANUSA Peritoneal Dialysis Study Group. Relative contribution of residual renal function and peritoneal clearance to adequacy of dialysis: a reanalysis of the CANUSA study. J Am Soc Nephrol. 2001;12(10):2158-2162.

40. Brown EA, Davies SJ, Rutherford P, et al; EAPOS Group. Survival of functionally anuric patients on automated peritoneal dialysis: the European APD Outcome Study. J Am Soc Nephrol. 2003;14(11):2948-2957.

41. Shemin D, Bostom AG, Laliberty P, Dworkin LD. Residual renal function and mortality risk in hemodialysis patients. Am J Kidney Dis. 2001;38(1):85-90.

42. Szeto CC, Wong TY, Chow KM, Leung CB, Li PK. Are peritoneal dialysis patients with and without residual renal function equivalent for survival study? Insight from a retrospective review of the cause of death. Nephrol Dial Transplant. 2003;18(5):977-982.
43. Termorshuizen F, Dekker FW, van Manen JG, Korevaar JC, Boeschoten EW, Krediet RT; NECOSAD Study Group. Relative contribution of residual renal function and different measures of adequacy to survival in hemodialysis patients: an analysis of The Netherlands Cooperative Study on the Adequacy of Dialysis (NECOSAD)-2. J Am Soc Nephrol. 2004;15(4):1061-1070.

44. Termorshuizen F, Korevaar JC, Dekker FW, van Manen JG, Boeschoten EW, Krediet RT; NECOSAD Study Group. The relative importance of residual renal function compared with peritoneal clearance for patient survival and quality of life: an analysis of The Netherlands Cooperative Study on the Adequacy of Dialysis (NECOSAD)-2. Am J Kidney Dis. 2003;41(6):1293-1302.

45. Li PK, Chow KM, Wong TY, Leung CB, Szeto CC. Effects of an angiotensin-converting enzyme inhibitor on residual renal function in patients receiving peritoneal dialysis. A randomized, controlled study. Ann Intern Med. 2003;139(2):105-112.

46. Moist LM, Port FK, Orzol SM, et al. Predictors of loss of residual renal function among new dialysis patients. J Am Soc Nephrol. 2000;11(3): $556-564$.

47. Misra M, Vonesh E, Van Stone JC, Moore HL, Prowant B, Nolph KD. Effect of cause and time of dropout on the residual GFR: a comparative analysis of the decline of GFR on dialysis. Kidney Int. 2001;59(2): 754-763.

48. Lang SM, Bergner A, Töpfer M, Schiffl H. Preservation of residual renal function in dialysis patients: effects of dialysis-technique-related factors. Perit Dial Int. 2001;21(1):52-57.

49. Li PK, Szeto CC, Piraino B, et al; International Society for Peritoneal Dialysis. Peritoneal dialysis-related infections recommendations: 2010 update. Perit Dial Int. 2010;30(4):393-423.

50. Kim DK, Yoo TH, Ryu DR, et al. Changes in causative organisms and their antimicrobial susceptibilities in CAPD peritonitis: a single center's experience over one decade. Perit Dial Int. 2004;24(5):424-432.

51. Pérez Fontan M, Rodríguez-Carmona A, García-Naveiro R, Rosales M, Villaverde P, Valdés F. Peritonitis-related mortality in patients undergoing chronic peritoneal dialysis. Perit Dial Int. 2005;25(3):274-284.

52. van Esch S, Krediet RT, Struijk DG. 32 years' experience of peritoneal dialysis-related peritonitis in a university hospital. Perit Dial Int. 2014;34(2):162-170.

53. Piraino B, Bernardini J, Brown E, et al. ISPD position statement on reducing the risks of peritoneal dialysis-related infections. Perit Dial Int. 2011;31(6):614-630.

54. Bertoli SV, Musetti C, Ciurlino D, et al. Peritoneal ultrafiltration in refractory heart failure: a cohort study. Perit Dial Int. 2014;34(1):64-70.

55. Courivaud C, Kazory A, Crépin T, et al. Peritoneal dialysis reduces the number of hospitalization days in heart failure patients refractory to diuretics. Perit Dial Int. 2014;34(1):100-108.

56. Rizkallah J, Sood MM, Reslerova M, et al. Reduced hospitalizations in severe, refractory congestive heart failure with peritoneal dialysis: a consecutive case series. Clin Nephrol. 2013;80(5):334-341.

57. Koch M, Haastert B, Kohnle M, et al. Peritoneal dialysis relieves clinical symptoms and is well tolerated in patients with refractory heart failure and chronic kidney disease. Eur J Heart Fail. 2012;14(5):530-539.

58. Núñez J, González M, Miñana G, et al. Continuous ambulatory peritoneal dialysis as a therapeutic alternative in patients with advanced congestive heart failure. Eur J Heart Fail. 2012;14(5):540-548.

59. Cnossen TT, Kooman JP, Krepel HP, et al. Prospective study on clinical effects of renal replacement therapy in treatment-resistant congestive heart failure. Nephrol Dial Transplant. 2012;27(7):2794-2799.

60. Stack AG, Molony DA, Rahman NS, Dosekun A, Murthy B. Impact of dialysis modality on survival of new ESRD patients with congestive heart failure in the United States. Kidney Int. 2003;64(3):1071-1079

61. Sens F, Schott-Pethelaz AM, Labeeuw M, Colin C, Villar E; REIN Registry. Survival advantage of hemodialysis relative to peritoneal dialysis in patients with end-stage renal disease and congestive heart failure. Kidney Int. 2011;80(9):970-977. 
62. Helanterä I, Haapio M, Koskinen P, Grönhagen-Riska C, Finne P. Employment of patients receiving maintenance dialysis and after kidney transplant: a cross-sectional study from Finland. Am J Kidney Dis. 2012;59(5):700-706.

63. Julián-Mauro JC, Cuervo J, Rebollo P, Callejo D. Employment status and indirect costs in patients with renal failure: differences between different modalities of renal replacement therapy. Nefrologia. 2013;33(3): 333-341.

64. Muehrer RJ, Schatell D, Witten B, Gangnon R, Becker BN, Hofmann RM. Factors affecting employment at initiation of dialysis. Clin J Am Soc Nephrol. 2011;6(3):489-496.

65. Purnell TS, Auguste P, Crews DC, et al. Comparison of life participation activities among adults treated by hemodialysis, peritoneal dialysis, and kidney transplantation: a systematic review. Am J Kidney Dis. 2013;62(5):953-973.

66. Griva K, Kang AW, Yu ZL, et al. Quality of life and emotional distress between patients on peritoneal dialysis versus community-based hemodialysis. Qual Life Res. 2014;23(1):57-66.

67. Merkus MP, Jager KJ, Dekker FW, Boeschoten EW, Stevens P, Krediet RT. Quality of life in patients on chronic dialysis: self-assessment 3 months after the start of treatment. The Necosad Study Group. Am J Kidney Dis. 1997;29(4):584-592.

68. Wu AW, Fink NE, Marsh-Manzi JV, et al. Changes in quality of life during hemodialysis and peritoneal dialysis treatment: generic and disease specific measures. J Am Soc Nephrol. 2004;15(3):743-753.

69. Cameron JI, Whiteside C, Katz J, Devins GM. Differences in quality of life across renal replacement therapies: a meta-analytic comparison. Am J Kidney Dis. 2000;35(4):629-637.

70. Brown EA, Johansson L, Farrington K, et al. Broadening Options for Long-term Dialysis in the Elderly (BOLDE): differences in quality of life on peritoneal dialysis compared to haemodialysis for older patients. Nephrol Dial Transplant. 2010;25(11):3755-3763.

71. Rubin HR, Fink NE, Plantinga LC, Sadler JH, Kliger AS, Powe NR. Patient ratings of dialysis care with peritoneal dialysis vs hemodialysis. JAMA. 2004;291(6):697-703.

72. Brown EA. Peritoneal dialysis for older people: overcoming the barriers. Kidney Int Suppl. 2008;(108):S68-S71.

73. Brown EA. Can quality of life be improved for the increasing numbers of older patients with end-stage kidney disease? Expert Rev Pharmacoecon Outcomes Res. 2010;10(6):661-666.

74. Just PM, Riella MC, Tschosik EA, Noe LL, Bhattacharyya SK, de Charro F. Economic evaluations of dialysis treatment modalities. Health Policy. 2008;86(2-3):163-180.
75. Karopadi AN, Mason G, Rettore E, Ronco C. Cost of peritoneal dialysis and haemodialysis across the world. Nephrol Dial Transplant. 2013;28(10):2553-2569

76. Baboolal K, McEwan P, Sondhi S, Spiewanowski P, Wechowski J, Wilson $\mathrm{K}$. The cost of renal dialysis in a UK setting - a multicentre study. Nephrol Dial Transplant. 2008;23(6):1982-1989.

77. Berger A, Edelsberg J, Inglese GW, Bhattacharyya SK, Oster G. Cost comparison of peritoneal dialysis versus hemodialysis in end-stage renal disease. Am J Manag Care. 2009;15(8):509-518.

78. Chavers BM, Solid CA, Gilbertson DT, Collins AJ. Infection-related hospitalization rates in pediatric versus adult patients with end-stage renal disease in the United States. J Am Soc Nephrol. 2007;18(3): 952-959.

79. Lee H, Manns B, Taub K, et al. Cost analysis of ongoing care of patients with end-stage renal disease: the impact of dialysis modality and dialysis access. Am J Kidney Dis. 2002;40(3):611-622.

80. Chui BK, Manns B, Pannu N, et al. Health care costs of peritoneal dialysis technique failure and dialysis modality switching. Am J Kidney Dis. 2013;61(1):104-111.

81. Duong U, Kalantar-Zadeh K, Molnar MZ, et al. Mortality associated with dose response of erythropoiesis-stimulating agents in hemodialysis versus peritoneal dialysis patients. Am J Nephrol. 2012;35(2): 198-208.

82. Dratwa M. Costs of home assistance for peritoneal dialysis: results of a European survey. Kidney Int Suppl. 2008;(108):S72-S75.

83. Laplante S, Krepel H, Simons B, Nijhoff A, van Liere R, Simons M. Offering assisted peritoneal dialysis is a cost-effective alternative to the current care pathway in frail elderly Dutch patients. Int $J$ Healthc Manag. 2013;6(1):27-36.

84. Vanholder R, Davenport A, Hannedouche T, et al; Dialysis Advisory Group of American Society of Nephrology. Reimbursement of dialysis: a comparison of seven countries. J Am Soc Nephrol. 2012;23(8): 1291-1298.

85. Kleophas W, Reichel H. International study of health care organization and financing: development of renal replacement therapy in Germany. Int $J$ Health Care Finance Econ. 2007;7(2-3):185-200.

86. Mendelssohn DC, Langlois N, Blake PG. Peritoneal dialysis in Ontario: a natural experiment in physician reimbursement methodology. Perit Dial Int. 2004;24(6):531-537.

\section{Publish your work in this journal}

The International Journal of Nephrology and Renovascular Disease is an international, peer-reviewed open-access journal focusing on the pathophysiology of the kidney and vascular supply. Epidemiology, screening, diagnosis, and treatment interventions are covered as well as basic science, biochemical and immunological studies. The journal welcomes

\section{Dovepress}

original research, clinical studies, reviews \& evaluations, expert opinion and commentary, case reports and extended reports. The manuscript management system is completely online and includes a very quick and fair peerreview system, which is all easy to use. Visit http://www.dovepress.com/ testimonials.php to read real quotes from published authors. 